\title{
Editorial Introduction-How Sports Can Help Economics
}

\author{
Ruud H. Koning ${ }^{1} \cdot$ Jan C. van Ours ${ }^{2,3,4}$
}

Accepted: 9 November 2020 / Published online: 20 November 2020

(c) Springer Science+Business Media, LLC, part of Springer Nature 2020

Sports economics is an area of research that is important also for economists who are not interested in sports per se. Kahn (2000) argued that the analysis of sports data can help understand economic mechanisms when it comes to for example the relationship between effort and reward, the influence of monopsony power on wages of workers and the influence of incentives on behavior. Palacios-Huerta (2014) in his book on beautiful game theory- "How soccer can help economics"-also mentioned interesting areas of economic research for which sports data can be helpful. Focusing on football data he discusses issues like minimax strategies (analyzing penalty kicks), performance under pressure (investigating penalty shootouts), social pressure on referees (looking at injury time added at the end of a game), and tastebased discrimination (studying league standings and relative wage bills).

By now, sports economics is a well-established sub discipline of economics (it has its own JEL-codes, Z20, Z21, Z22, Z23, Z28, and Z29), and sports has been proven to be an excellent laboratory for economics. After all, there is not so much ambiguity about the objective of athletes or teams (they want to win). This special issue of De Economist is devoted to sports economics. We present six papers that illustrate sports as an important area of application of economic analysis.

The first article is by Bernd Frick, who compares risk-taking behavior of men and women in extreme sports. Surveys suggest that generally women are more riskaverse than men. Interestingly, he finds that-conditional on participation in cliff diving and free diving - men and women do not differ significantly in their preferences for sensation-seeking behavior. This is in line with studies among managers where female CEOs' mental dispositions do not seem to differ from their male peers

Jan C. van Ours

vanours@ese.eur.nl

1 Department of Economics, Econometrics and Finance, Faculty of Economics and Business, University of Groningen, Groningen, The Netherlands

2 Erasmus School of Economics, Tinbergen Institute, Erasmus Center for Applied Sports Economics (ECASE), Erasmus University Rotterdam, Rotterdam, The Netherlands

3 Department of Economics, University of Melbourne, Parkville, Australia

4 CEPR, London, UK 
suggesting that self-selection into leadership positions is comparable to self-selection into high-risk sports.

In the second article, Sanne Joustra, Ruud Koning, and Alex Krumer test whether later participants in elite gymnastics events obtain a higher execution score than gymnasts performing earlier. The laboratory environment of sports is especially relevant here, as order of performance is randomized in these events. Female gymnasts who perform later receive on average a significantly higher execution score, and this effect is not found for male gymnasts. Potentially, this gender difference is due to the existence of subjective evaluation of artistry only in female competitions.

Stefan Szymanski studies the effects on football ticket prices of the introduction of Value Added Taxes (VAT) in the United Kingdom in April 1973. Clubs stated publicly that they would pass on the tax to customers in full in the form of higher prices. However, since professional football clubs back then were local monopolists, tax theory would predict that the VAT should be absorbed in full by the clubs, i.e. ticket prices should not be affected. The analysis shows that taxes were only passed on to a limited extent, which was contrary to both public announcements and prediction from theory.

James Reade and Meshael Batarfi take a broader, more international perspective identifying variation in performance of national soccer teams. Why are some countries very good, and who do others perform so poorly? A countries' GDP per capita has a significant positive impact on winning proportion, whereas population size is negatively related to the win proportion of the national team. Experience as measured by the total number of matches played has a positive effect.

The labor market for head coaches is studied by Alex Bryson, Babatunde Buraimo, Alex Farnell, and Rob Simmons. When is the relation between the soccer team and the coach terminated? A coach can quit when better alternatives are available or may be fired when results are disappointing. They find that a coach is less likely to be dismissed if the team is performing better than expected. However, they also find that a coach is less likely to quit voluntarily if the team is performing better than expected. Again, sports is an interesting laboratory, because we can distinguish separation of the coach and the team into quits and dismissals, unlike in most other labor market research.

Finally, home advantage, an important phenomenon of elite sports, is studied by Thomas Peeters and Jan van Ours. They explain the long-term development of relative and absolute home advantage in the English Premier League. They find that some teams have a persistently higher home advantage, and moreover, different managers enjoy different levels of home advantage in their career. Absolute home advantage has decreased markedly over time, unrelated to, for example, technical innovations to support refereeing decisions.

Finally, we mention that contributions to this special issue were collected in the fall of 2019. The importance of sports was underlined during the lockdowns caused by the corona pandemic in 2020: television stations were without content! The exogenous shock of the pandemic will undoubtedly lead to new papers (Has home advantage disappeared in matches without audience?), but the timing of this issue has not allowed the authors to incorporate these new developments. 


\section{References}

Kahn, L. M. (2000). The sports business as a labor market laboratory. Journal of Economic Perspectives, 14(3), 75-94.

Palacios-Huerta, I. (2014). Beautiful game theory: How soccer can help economics. Princeton: Princeton University Press.

Publisher's Note Springer Nature remains neutral with regard to jurisdictional claims in published maps and institutional affiliations. 